\title{
The relationship between social comparison and depressive symptoms among Indonesian Instagram users
}

\author{
Las Asimi Lumban $\mathrm{Gaol}^{1}$, Amira Budi Mutiara ${ }^{2 *}$, Nimas Linggar Saraswati ${ }^{3}$, Rizqika Rahmadini ${ }^{4}$, Maulidia \\ Annisa Hilmah ${ }^{5}$ \\ 1,2,3,4,5 Faculty of Psychology, University of Indonesia, Kampus UI Depok, 16424, Indonesia \\ *E-mail: amira.budi@ui.ac.id
}

\begin{abstract}
Instagram is one of the most popular social media platforms in the world. In Indonesia, Instagram has more than 22 million monthly active users. However, its use may increase depressive symptoms due to negative social interaction, particularly social comparison. We hypothesized that social comparison was negatively correlated with depressive symptoms. Using an online questionnaire platform, 131 participants aged 18-28year-old were recruited. Depressive symptoms were measured using the Center of Epidemiological Studies Depression (CES-D) scale by Radloff (1977) and social comparison was measured with Social Comparison Rating Scale (Allan \& Gillbert, 1995) adapted by Feinstein et al. (2013). A significant correlation between social comparison and depressive symptoms was found. Moreover, a significant correlation between percentage of strangers followed and social comparison was found, while the correlation between frequency of Instagram use and social comparison was not significant. These findings indicate that social comparison occurs in spite of various time spent in using Instagram and might occur more frequently with a higher number of strangers followed. Instagram users should become aware that Instagram could facilitate negative social comparison which may result in depressive symptoms, so they should use Instagram cautiously.
\end{abstract}

\section{Keywords: depressive symptoms, Instagram, social comparison, social media}

\section{Introduction}

The use of social media has been increasing in the past few years with a $25 \%$ increase from 2015 to 2017 alone, which means 37\% (2.80 billion people) of the world population are today active social media users (Kemp, 2017). The main reason for the numbers is the fast development of technology and information sharing through the internet and the easy access to the social media. The easy access results in around $91 \%$ of $16-24$ year-olds use internet for social networking (Royal Society for Public Health, 2017).

Since social media has become inseparable components of youth's everyday lives, the impact of social media on its users has been long discussed and studied in the field of psychology. Most of the impacts are found negatively influencing to mentalhealth, for example addiction, loneliness, cyberbullying (alongside texting, which could lead to depression and anxiety), sleep disturbance, body- image issues, and depression (Attwood, 2013; Cabral, 2008; Davey, 2016; Levenson, Shensa, Sidani, Colditz \& Primack, 2016; Royal Society for Public Health, 2017; Sidani, Shensa, Radovic, Miller, Colditz, Hoffman, \& Primack, 2016; Song, Larose, Eastin, \& Lin, 2004; Whittaker \& Kowalski, 2015).

Until now, one of the most studied social media is still Facebook since this platform has billion monthly active users years after it was launched in February 2004. A review article was done by reviewing approximately 412 research articles in 5 categories of study, including the descriptive analysis of the users, motivations for using Facebook, self-presentation, Facebook's role as a platform for social interactions, and privacy and information disclosure until 2012 (Wilson, Gosling, \& Graham, 2012). But recent studies are shifting into studying the influence of the new popular social media, Instagram. One of the shifting reasons might be the growing number of users accounted for 
millennials and Gen Z. In 2016, roughly $59 \%$ of 18 29-year-old adults in the U.S. were using Instagram and this age cohort dominated among Instagram users (Greenwood, Perrin, \& Duggan, 2016).

\subsection{Instagram}

Today, Instagram is one of the popular social media platforms among social media users. Based on its active users, Instagram globally has more than 600 million users around the world with an increase of 100 million users within six months (June December 2016) (Smart Insights, 2017; Yusuf, 2016). In Indonesia, Parikesit (2016) stated that Instagram has 22 million monthly users with the largest users' age between $18-24$ years (59\%) and more than half of users are female $(63 \%)$.

Instagram main features are photo and video sharing. These features allow its users to also produce their own photos and videos contents. Frequently published content by users in Indonesia includes selfie photos $(>50 \%)$, visited places $(55 \%)$, travelling photos $(53 \%)$, photo or video of friends and family (50\%), food (40\%), showed off newly purchased item (>20\%) (Parikesit, 2016). The photos and videos that are published can be seen on the timeline and feedbacks can be given through likes and comments by other users. Other features which include photo filters to beautify themselves, tag other users to their photos and videos, published Instagram content to other social media, and share photos and videos temporally by using one of the feature in Instagram, namely Instagram story. However, besides these great features, there are several researchers that show Instagram actually has negative effects to mental health (Fardouly \& Vartanian, 2016; Lup, Trub, \& Rosenthal, 2015; Mullin, 2017; Royal Society for Public Health, 2017).

The Royal Society for Public Health (2017) conducted a research regarding the positive and negative impacts of popular social media such as Facebook, YouTube, Twitter, Snapchat, and Instagram. The negative impacts measured are anxiety, depression, loneliness, (lack of) sleep, body image (issues), real-world relationships, bullying, and FOMO. Accounting all those negative impacts, Instagram comes out as the worst social media for young's mental health (Royal Society for Public Health, 2017). They also suggested that young people who are heavy users of Instagram are prone to psychological distress including anxiety and depression (Royal Society for Public Health, 2017).
Symptoms of social anxiety in young people particularly linked with operating more than one account simultaneously (Becker, Alzahabi, \& Hopwood, 2013). As well as anxiety disorders, approximately 80,000 young people in the UK suffer from severe depression (Green, McGinnity, Meltzer, Ford, \& Goodman, 2005). Meanwhile in 2015, nearly 3 million adolescents aged 12 to 17 in the United States had at least one major depressive episode in the past year (National Institute of Mental Health, 2015). Thus, there is growing evidence linking social media use and depression in young people, with studies showing that negatively comparing oneself with others is associated with significantly increased odds of depressive symptoms.

\subsection{Depressive Symptoms}

Depression is a common mood disorder that affects as much as $3.7 \%$ of the Indonesian population and it means that 9 million people out of 250 million suffer from depression (Suryanis, 2017). Symptoms include sad mood, lack of motivation and activity, negative self-concept, loss of hope, and decreased sleep and appetite (Uhlir, 2016). According to DSM-5 by American Psychiatric Association (2013), "depression is defined by the presence of five or more specific symptoms from a list of nine symptoms occurring within the same 2-week period and show a change from previous functioning, with at least one of the symptoms pertaining to a depressed mood or loss of interest or pleasure".

Even though there is no agreement as to what causes depression, there are various factors contributing to depression. Whether it is hereditary or learned, it could be a combination of both. Many different factors and life circumstances can act as potential triggers which may prompt depressive symptoms specifically in young people; these include genetics or pubertal hormones (Eley, Sugden, Corsico, Gregory, Sham, McGuffin, 2004), inherited traits (Terracciano et al., 2010), and negative social interaction (Chou, Liang, Sareen, 2011; Schuster, Kessler, Aseltine, 1990; Teo, Choi, Valenstein, 2013; Yapko, 2003).

From all factors underlying depression mentioned, negative social interaction might be a factor that is easier to modify than the rest. Therefore, it is important for young people to be attentive if they are involved in negative social interaction. Once they are aware of it, they can learn to improve their social skills and get more rewards from social 
support, which in turn may help them get over depression (Hokanson \& Butler, 1992). There is also strong evidence that various kinds of social interactions (including finding and utilizing social support) are linked to social comparison processes (Brewin, 2013).

\subsection{Social Comparison}

Human has the drive to evaluate his opinions and his abilities, furthermore, when objective non-social methods are not available to make the evaluation, people tend to compare their opinions and abilities with others (Festinger, 1954). That action of comparing can be called social comparison. Social comparison itself can have many outcomes, such as influencing a person's self-concept, level of aspiration, and feelings of well-being (e.g. subjective well-being) (Suls, Martin, \& Wheeler, 2002).

Instagram as an online social media provides the mean to socially compare oneself to other users. Users of Instagram can make comparative evaluation between themselves and other users by viewing others' posts (e.g. place of the post, number of likes, etc.) and profiles (e.g. number of followers). The impact of social comparison depends on whether users engage in upward or downward social comparison which yields different outcomes.

According to Festinger's (1954) social comparison theory, when people choose a target for comparison, they commonly prefer others who appear to have better trait or ability than they do, a tendency called upward drive or upward social comparison. Upward social comparison occurs when we prefer to compare ourselves to others who are perceived socially better than ourselves (Gibbons \& Gerrard, 1989). The reason for this preference is that people who are better than us are considered more likely to provide useful information that can facilitate our improvement in the dimensions or behavior that is being compared (Gibbons, 1986).

However, in one of the modifications of social comparison theory, it is suggested that upward social comparison does not occur for some people in some situations (Brickman \& Bulman, 1977). The upward social comparison can be motivating, but it usually leads to feelings of inadequacy. That is why this kind of comparison is also called a negative comparison because it infers that someone feels more negative (i.e. inferior, unliked, less attractive, etc.) if compared to others. This is especially true for people who may feel threatened when looking at others who are better off and they choose to avoid such people and choose to do a comparison with others who are worse than they are, a process called downward social comparison (Gibbons, 1986).

In a study conducted by Wheeler and Miyake (1992), it was found that upward social comparison predicts an increase in negativity of affect while downward social comparison predicted increased positivity. In the context of social networking, it was also found that downward social comparison would be associated with higher self-esteem and positive feelings while comparing oneself negatively with others may also place individuals at risk for rumination, which in turn, was associated with increases in depressive symptoms (Feinstein, Hershenberg, Bhatia, Latack, Meuwly, \& Davila, 2013).

This applies especially in Instagram, where photos posted by our followings mostly reflect their good parts of their lives only, making upward social comparison nearly impossible to avoid. For instance, once a person opens the Instagram app, he or she might feel threatened by seeing graduation photos posted by friends while he or she had difficulties with final thesis, then he or she might feel negative about his or herself in that domain. Since upward social comparison might increase the possibility of depressive symptoms to build and emerge (especially in social networking), we decided to conduct this research on Instagram, the worst social media that influences the younger generation and an online platform that can easily be used to compare oneself with another.

From the findings above, we can conclude that there is an increasing number of social media users in Indonesia, especially in the young generation. On the other hand, no sufficient findings have been published regarding the impacts of social media usage that covers Indonesian users. Therefore, we are interested to study further regarding how Instagram as one of the popular social media in Indonesia impacts the users.

\subsection{The Aim of Study}

The present study aims to find the relationship between social comparison and depressive symptoms among Indonesian Instagram users. While few studies have investigated Instagram use and depression, Lup, Trub, and Rosenthal (2015) 
found that negatively comparing oneself with others on Instagram was associated with higher depressive symptoms. In light of these findings, we hypothesize that the more negative someone feels compared to other people in Instagram, the more depressive symptoms one has.

H1. Respondents who compare themselves negatively with other users on Instagram will have higher depressive symptoms than those who mostly compare themselves in a positive way.

However, based on previous researchers (e.g. Appel, Gerlach, \& Crusius, 2016; Lup, Trub, \& Rosenthal, 2015), we also suspect there are other factors that are affecting the social comparison, including frequency of Instagram use, percentage of strangers followed, and gender. Thus, we include them as a control variable as they may affect the relationship between social comparison and depressive symptoms.

\section{Methods}

\subsection{Sample}

Participants were 18-28 years old who identified themselves as Instagram users. There were 131 participants who voluntarily participated to fill the online questionnaire that was spread through personal social media. All participants were included in the analysis (77,1\% female; $17,6 \%$ male; $5,3 \%$ refused to state their gender) and most of them are in their 20s $(M=20,09, S D=1,56)$.

Most of the participants used Instagram for more than 3 hours per day (24\%) followed by 31-60 minutes per day (19\%) and 2-3 hours per day $(17 \%)$. The mean percentage of strangers followed were $33.6 \%$ from the sample.

\subsection{Research Design}

A cross-sectional survey design was used.

\subsection{Instruments and Measurements}

\subsubsection{Instagram use}

Participants stated how much time they usually spend on Instagram daily by selecting one of the choices given: 10 minutes or less, 11-30 minutes, 31-60 minutes, 1-2 hours, and 2-3 hours (Lup et al., 2015).

\subsubsection{Percentage of strangers followed}

Participants reported the estimate of how many strangers they follow compared to all of the accounts they follow using a percentage number ranging from $0 \%$ (no strangers followed) to $100 \%$ (all of the users they followed are strangers).

\subsubsection{Social comparison}

Social Comparison Rating Scale (Allan \& Gillbert, 1995) adapted by Feinstein et al. (2013) to measure the tendency to compare with others socially on Facebook, which was then adjusted by Lup et al. (2015) to be used on Instagram users was used to measure social comparison $(\alpha=0.87)$. The scale began with "When I compare myself to other people in Instagram, I feel..." (Indonesian translation: "Ketika saya membandingkan diri saya dengan orang lain di Instagram, saya merasa...") then continued with 11 bipolar statements that the participants could choose using a 10-points Likertscale. The statements examples are "inferior" to "superior" and "unlikeable" to "more likable" .

\subsubsection{Depressive symptoms}

Center of Epidemiological Studies Depression (CES-D) scale by Radloff (1977) was used to measure depressive symptoms of participants. Participants responded to the 20 -item scale ranging from $1=$ "rarely or none of the time" to $4=$ "most or all of the time" about how they felt in the past week. The score of each item was then summed. Example of an item in CES-D is "I was bothered by things that usually don't bother me" (Indonesian translation: "Saya terganggu dengan hal-hal yang biasanya tidak mengganggu saya.") $(\alpha=0.93)$.

\subsection{Procedure}

All of the scales were merged in a questionnaire made online in Google Form. A call for participants were shared through our personal social media, such as LINE and Instagram, which then shared by other users from May 22 to May 24, 2017. Participants stated their consents to participate in this study and stated that they live in Jakarta, Bogor, Depok, Tangerang, and Bekasi (Jabodetabek) area before answering the questionnaire. They were also given the chance to participate in a draw to win a top-up credit of Rp25,000 prized for two persons. All of the data measured were then analyzed using IBM SPSS Statistics v.21. 


\section{Results}

Tests for normality were conducted to all variables and they showed non-normal distributions except for social comparison. Therefore, the correlation analyses were conducted with Spearman's Rank Order Correlation.

\subsection{Social comparison and depressive symptoms}

At first, we tested the main hypothesis of this study. Spearman's Rank Order Correlation was used to analyze the correlation between social comparison and depressive symptoms. A significant correlation was found $\left(r_{s}=-0.48, p<0.01\right)$, the result is presented in Table 3.1. and is in line with our hypothesis.

\subsection{Control variables and social comparison}

Then, we examined the relationship between variables that probably would have impacts on social comparison and depressive symptoms as a method of control. Those variables were frequency of Instagram use, percentage of strangers followed, and gender. The results are presented in Table 3.2.

We found no significant correlation between frequency of Instagram use and social comparison $\left(r_{s}=0.016, p>0.05\right)$. This indicated that social comparison occurs in spite of various time spent on Instagram. But, there was a significant correlation between percentage of strangers followed and social comparison $\left(r_{s}=-0.21, p<0.05\right)$ which indicated that higher number of strangers followed may increase the chance of negative social comparison to occur. There was no significant difference of social comparison between male and female $t(122)=1.08$, $p>0.05$.

\subsection{Control variables and depressive symptoms}

There was no significant correlation between frequency of Instagram use and depressive symptoms $\left(r_{s}=0.02, p>0.05\right)$. Similarly, there was no significant correlation between percentage strangers followed and depressive symptoms $\left(r_{s}=\right.$ $0.12, p>0.05)$. Lastly, there was also no significant difference in depressive symptoms between male and female $t(122)=-0.18, p>0.05$.
Table 3.1

Spearman Rank-order Correlation between all variables

$\begin{array}{cc}\text { Social } & \text { Depressive } \\ \text { Comparison } & \text { Symptoms }\end{array}$

\begin{tabular}{lcc}
\hline $\begin{array}{l}\text { Social } \\
\text { Comparison }\end{array}$ & - & $-0.484^{* *}$ \\
$\begin{array}{l}\text { Percent of } \\
\text { strangers } \\
\text { followed }\end{array}$ & $-0.210^{*}$ & 0.122 \\
$\begin{array}{l}\text { Frequency of } \\
\text { Instagram use }\end{array}$ & 0.016 & -0.026 \\
\hline
\end{tabular}

Table 3.2

Independent Sample t-Test on Gender between Social Comparison and Depressive Symptoms

\begin{tabular}{lccccccccc} 
& \multicolumn{3}{c}{ Male } & \multicolumn{7}{c}{ Female } & & \\
\cline { 2 - 7 } & $M$ & $S D$ & $n$ & $M$ & $S D$ & $n$ & $t$ & $p$ \\
\hline $\begin{array}{l}\text { Social } \\
\text { Comparison }\end{array}$ & 65.43 & 12.47 & 23 & 62.08 & 13.65 & 101 & 1.08 & 0.28 \\
$\begin{array}{l}\text { Depressive } \\
\text { Symptoms }\end{array}$ & 39.30 & 10.68 & 23 & 39.72 & 9.67 & 101 & -0.18 & 0.86
\end{tabular}

* Correlation is significant at the 0,05 level (2-tailed)

** Correlation is significant at the 0,01 level ( 1 -tailed)

\section{Discussion \& Conclusion}

Discussion. The result of this study proved our hypothesis which stated that there was a negative correlation between social comparison in Instagram and depressive symptoms. The more negative people feel in comparison to others in Instagram, the more depressive symptoms they have. Lup, et al. (2015) also found the same negative association between social comparison and depressive symptoms in Instagram. Moreover, this finding corresponded to another study of social comparison in Facebook by Feinstein et al. (2013). They found that comparing oneself negatively with others may made them at risk for rumination and as the result, depressive symptoms. In addition, there is also another study by Ascone et al. (2016) that found short-term exposure to others who are inferior or superior can change the immediate subjective perception of ones' social position. Furthermore, that study also found that the threat towards one's social rank is more likely followed by negative impact towards mental health in individuals who already show signs of vulnerability. 
However, individual differences also play a role when comparing oneself with others in social media. People with high Social Comparison Orientation (SCO), compared to low-SCO individuals, tend to be affected more negatively by contents in Facebook (Vogel, Rose, Okdie, Eckles, \& Franz, 2015) and Instagram (de Vries, Möller, Wieringa, Eigenraam, \& Hamelink, 2016). Further study could inspect how SCO could affect the relation between social comparison and depressive symptoms outside the experimental condition. Furthermore, future studies conducted longitudinally are still needed to prove that negatively comparing oneself to others in social media may cause more depressive symptoms. As this current study is only correlational, this finding may not imply a causal relationship. This study does not restrict the probability that people who have more depressive symptoms are more prone to negative social comparisons.

As we expected, our control variables, the frequency of Instagram use and number of strangers followed, was not related to depressive symptoms. Our results are not in line with previous studies among Facebook users which found the increased amount of time spent on Facebook predicted decline in subjective well-being and more negative mood (Kross et al., 2013; Sagioglou \& Greitemeyer, 2014). Thus, when spending time on Instagram, the quality and engagement need to be considered more than the quantity of time spent.

Unlike frequency of Instagram use, which was not associated with both social comparison and depressive symptoms, percentage of strangers followed was actually associated with a more negative social comparison. This finding is somewhat in line with Lup, et al. (2015). They found that the number of strangers followed moderated the relation between Instagram use and social comparison; but it's only valid in people with highest and lowest levels of strangers followed. In sum, this current study found that the frequency of Instagram use among Indonesian was not correlated with social comparison but the percentage of strangers followed alone was associated with social comparison among all participants. This indicates that how Indonesians use Instagram may be different from Americans.

We assume that difference in collectivism value between participants in this study and participants in Lup, et al. (2015) study in America may be the cause. People with high collectivistic background are found to be seeking more social comparison (particularly upward) as the study of White \& Lehman (2005) found. Thus, as an Asian nation high in collectivism (Hofstede, n.d.), Indonesians may seek more social comparison than Americans. Further study towards how collectivistic culture act upon social comparison through social media and how it corresponds to negative consequences is suggested to understand more about Indonesian or even Asian users' behavior in social media.

Further research could examine what impact the percentage of strangers followed on social comparison as the present study found a significant correlation between them.

Conclusions. Based on the results, it can be concluded that upward or negative social comparison increases the probability of depressive symptoms to be formed in users of Instagram. There was no gender difference in terms of doing social comparison. While higher frequency of Instagram use may not increase the chance of negative social comparison to occur, the number of strangers followed may. Someone's tendency to make a negative social comparison on Instagram might be seen through the number of strangers followed, this negative social comparison could lead to the forming of depressive symptoms.

The limitations of our study may have contributed to these results and can be considered for future studies. First, the majority of participants are female. This could influence the results in terms of difference between the genders in social comparison. For future studies, a more balanced ration between the genders may result in different findings. Second, the average age of our participants are near 20. This indicates the population of young Instagram users in Indonesia were not fully represented. Future studies can ensure the average age are somewhere around 23 or 24 (since the range are between 18-28 years old). Limited number of participants should also be considered, only 131 users were included from around 22 million active users in Indonesia. Third, there is a limitation regarding the method of data analysis. A more appropriate analytical technique would be polychoric correlation that accounts both the normal and non-normal distribution of the data.

With various improvements, future research is expected to further improve the understanding of Instagram users about the negative effects of Instagram so that they become more aware and able 
to control themselves to avoid negative social comparison and other factors that could have negative impact on their mental health.

\section{References}

Allan, S., \& Gilbert, P. (1995). A social comparison scale: Psychometric properties and relationship to psychopathology. Personality and Individual Differences, 19(3), 293-299.

American Psychiatric Association. (2013). Diagnostic and statistical manual of mental disorders (DSM5®). American Psychiatric Pub.

Appel, H., Gerlach, A. L., \& Crusius, J. (2016). The interplay between Facebook use, social comparison, envy, and depression. Current Opinion in Psychology, 9, 44-49.

Ascone, L., Jaya, E. S., \& Lincoln, T. M. (2016). The effect of unfavorable and favorable social comparisons on paranoid ideation: An experimental study. Journal of Behavior Therapy and Experimental Psychiatry. https://doi.org/10.1016/j.jbtep.2016.08.002

Attwood, T. (2013). Why social media causes anxiety. [online] Anxiety.org. Available at: https://www.anxiety.org/social-media-causes-anxiety [Accessed 29 Jul. 2017].

Becker, M., Alzahabi, R., \& Hopwood, C. (2013). Media multitasking is associated with symptoms of depression and Social Anxiety. Cyberpsychology, Behavior, And Social Networking, 16(2), 132-135. http://dx.doi.org/10.1089/cyber.2012.0291

Brewin, C. R. (2013). Cognitive foundations of clinical psychology (psychology revivals). Psychology Press.

Brickman, P., \& Bulman, R. J. (1977). Pleasure and pain in social comparison. Social comparison processes: Theoretical and empirical perspectives, 149, 186.

Cabral, J. (2008). Is generation Y addicted to social media? Future of children, 18, 125.

Chou, K. L., Liang, K., \& Sareen, J. (2011). The association between social isolation and DSM-IV mood, anxiety, and substance use disorders: Wave 2 of the National Epidemiologic Survey on Alcohol and Related Conditions. The Journal of Clinical Psychiatry, 72(11), 1468-1476.

Davey, G. (2016). Social media, loneliness, and anxiety in young people. [online] Psychology Today. Available at: https://www.psychologytoday.com/blog/why-weworry/201612/social-media-loneliness-and-anxietyin-young-people [Accessed 29 Jul. 2017].

de Vries, D. A., Möller, A. M., Wieringa, M. S., Eigenraam, A. W., \& Hamelink, K. (2017). Social Comparison as the thief of joy: Emotional consequences of viewing strangers' instagram posts. Media Psychology, 1-24.

Eley, T. C., Sugden, K., Corsico, A., Gregory, A. M., Sham, P., McGuffin, P. (2004). Gene-environment interaction analysis of serotonin system markers with adolescent depression. Molecular Psychiatry, 9, 908-915.

Green, H., McGinnity, Á., Meltzer, H., Ford, T., \& Goodman, R. (2005). Mental health of children and young people in Great Britain, 2004.

Greenwood, S., Perrin, A., \& Duggan M. (2016). Social media update 2016: Facebook usage and engagement is on the rise, while adoption of other platforms holds steady. Accessed from http://www.pewinternet.org/2016/11/11/socialmedia-update-2016/

Fardouly, J., \& Vartanian, L. R. (2016). Social media and body image concerns: Current research and future directions. Current opinion in psychology, 9, 1-5.

Feinstein, B. A., Hershenberg, R., Bhatia, V., Latack, J. A., Meuwly, N., \& Davila, J. (2013). Negative social comparison on Facebook and depressive symptoms: Rumination as a mechanism. Psychology of Popular Media Culture, 2(3), 161.

Festinger, L. (1954). A theory of social comparison processes. Human Relations. 7, 117-140.

Gibbons, F. X. (1986). Social comparison and depression: company's effect on misery. Journal of personality and social psychology, 51(1), 140.

Gibbons, F. X., \& Gerrard, M. (1989). Effects of upward and downward social comparison on mood states. Journal of Social and Clinical Psychology, 8(1), 1431.

Hofstede, G. (n.d.). Indonesia - Geert Hofstede. Geerthofstede.com. Accessed 29 July 2017, from https://www.geert-hofstede.com/indonesia.html.

Hokanson, J. E., \& Butler, A. C. (1992). Cluster analysis of depressed college students' social behaviors. Journal of Personality and Social Psychology, 62(2), 273.

Kemp, S. (2017). Digital in 2017: Global Overview. Accessed from https://wearesocial.com/specialreports/digital-in-2017-global-overview.

Kross, E., Verduyn, P., Demiralp, E., Park, J., Lee, D. S., Lin, N., ... \& Ybarra, O. (2013). Facebook use predicts declines in subjective well-being in young adults. PloS one, 8(8), e69841.

Levenson, J. C., Shensa, A., Sidani, J. E., Colditz, J. B., \& Primack, B. A. (2016). The association between social media use and sleep disturbance among young adults. Preventive medicine, 85, 36-41.

Lup, K., Trub, L., \& Rosenthal, L. (2015). Instagram \#instasad?: Exploring associations among Instagram use, depressive symptoms, negative social 
comparison, and strangers followed.

Cyberpsychology, Behavior, And Social Networking, 18(5), 247-252.

http://dx.doi.org/10.1089/cyber.2014.0560

Mullin, A. C. (2017). \# Comparison: An examination of social comparison orientation on Instagram as it relates to self-esteem and state anxiety.

National Institute of Mental Health. (2015). Major depression among adolescents. Accessed from: https://www.nimh.nih.gov/health/statistics/prevalenc e/major-depression-among-adolescents.shtml [Accessed 30 Jul. 2017].

Parikesit, A. G. (2016). Fakta menarik pengguna instagram di indonesia. Accessed from https://www.cnnindonesia.com/teknologi/201601181 50454-188-105071/fakta-menarik-penggunainstagram-di-indonesia/.

Radloff, L. S. (1977). The CES-D scale: A self-report depression scale for research in the general population. Applied Psychological Measurement, 1(3), 385-401.

Royal Society for Public Health. (2017). Social media and young people's mental health and wellbeing. Retrieved from https://www.rsph.org.uk/uploads/assets/uploaded/62 be270a-a55f-4719-ad668c2ec7a74c2a.pdf

Sagioglou, C., \& Greitemeyer, T. (2014). Facebook's emotional consequences: Why facebook causes a decrease in mood and why people still use it. Computers in Human Behavior, 35, 359-363.

Schuster, T. L., Kessler, R. C., \& Aseltine, R. H. (1990). Supportive interactions, negative interactions, and depressed mood. American Journal of Community Psychology, 18(3), 423-438.

Sidani, J. E., Shensa, A., Radovic, A., Miller, E., Colditz, J. B., Hoffman, B. L., ... \& Primack, B. A. (2016). Association between social media use and depression among US young adults. Depression and Anxiety, 33(4), 323-331.

Smart Insights. (2017). Global social media research summary 2017. Accessed from http://www.smartinsights.com/social-mediamarketing/social-media-strategy/new-global-socialmedia-research/.

Song, I., Larose, R., Eastin, M. S., \& Lin, C. A. (2004). Internet gratifications and Internet addiction: On the uses and abuses of new media. Cyberpsychology \& Behavior, 7(4), 384-394.
Suls, J., Martin, R., \& Wheeler, L. (2002). Social comparison: Why, with whom, and with what effect?. Current directions in psychological science, 11(5), 159-163.

Suryanis, A. (2017). 9 juta orang di Indonesia mengalami depresi. Accessed from https://gaya.tempo.co/read/news/2017/05/21/060877 228/9-juta-orang-di-indonesia-mengalami-depresi.

Teo, A. R., Choi, H., \& Valenstein, M. (2013). Social relationships and depression: ten-year follow-up from a nationally representative study. PloS One, 8(4), e62396.

Terracciano, A., Tanaka, T., Sutin, A. R., Sanna, S., Deiana, B., Lai, S., ... \& Costa, P. T. (2010). Genome-wide association scan of trait depression. Biological Psychiatry, 68(9), 811-817.

Uhlir, J. L. (2016). Social comparison and selfpresentation on social media as predictors of depressive symptoms.

Vogel, E., Rose, J., Okdie, B., Eckles, K., \& Franz, B. (2015). Who compares and despairs? The effect of social comparison orientation on social media use and its outcomes. Personality And Individual Differences, 86, 249-256. http://dx.doi.org/10.1016/j.paid.2015.06.026

Wheeler, L., \& Miyake, K. (1992). Social comparison in everyday life. Journal of Personality and Social Psychology, 62(5), 760.

White, K., \& Lehman, D. R. (2005). Culture and social comparison seeking: The role of self-motives. Personality and Social Psychology Bulletin, 31(2), 232-242.

Whittaker, E., \& Kowalski, R. M. (2015). Cyberbullying via social media. Journal of School Violence, 14(1), 11-29.

Wilson, R. E., Gosling, S. D., \& Graham, L. T. (2012). A review of Facebook research in the social sciences. Perspectives on Psychological Science, 7(3), 203220.

Yapko, M. (2003). What Causes Depression?. [online] PsychologyToday. Accessed from: https://www.psychologytoday.com/articles/200307/ what-causes-depression [Accessed 8 Jul. 2017].

Yusuf, O. (2016). Pengguna Instagram tembus 600 juta. Accessed from http://tekno.kompas.com/read/2016/12/16/09060027/ pengguna.instagram.tembus.600.juta. 